\title{
Targeting the Metastatic Bone Microenvironment by MicroRNAs
}

\author{
Marie-Therese Haider and Hanna Taipaleenmäki* \\ Molecular Skeletal Biology Laboratory, Department of Trauma, Hand and Reconstructive Surgery, University Medical Center \\ Hamburg-Eppendorf, Hamburg, Germany
}

Bone metastases are a common and devastating feature of late-stage breast cancer. Metastatic bone disease is a consequence of disturbed bone remodeling due to pathological interactions between cancer cells and the bone microenvironment (BME). In the $\mathrm{BME}$, breast cancer cells severely alter the balanced bone formation and bone resorption driven by osteoblasts and osteoclasts. The complex cellular cross talk in the BME is governed by secreted molecules, signaling pathways and epigenetic cues including non-coding RNAs. MicroRNAs (miRNAs) are small non-coding RNAs that reduce protein abundance and regulate several biological processes, including bone remodeling. Under pathological conditions, abnormal miRNA signaling contributes to the progression of diseases, such as bone metastasis. Recently miRNAs have been demonstrated to

OPEN ACCESS

Edited by:

Julie A. Sterling,

Vanderbilt University,

United States

Reviewed by:

Graziana Colaianni,

University of Bari, Italy

Jennifer Tickner,

University of Western Australia,

Australia

*Correspondence:

Hanna Taipaleenmäki

h.taipaleenmaeki@uke.de

Specialty section:

This article was submitted

to Bone Research,

a section of the journal

Frontiers in Endocrinology

Received: 07 February 2018

Accepted: 11 April 2018

Published: 27 April 2018

Citation:

Haider M-T and Taipaleenmäki $H$ (2018) Targeting the Metastatic Bone Microenvironment by MicroRNAs.

Front. Endocrinol. 9:202. doi: 10.3389/fendo.2018.00202 regulate several key drivers of bone metastasis. Furthermore, miRNAs are implicated as important regulators of cellular interactions within the metastatic BME. As a consequence, targeting the BME by miRNA delivery or antagonism has been reported to limit disease progression in experimental and preclinical conditions positioning miRNAs as emerging novel therapeutic tools in metastatic bone disease. This review will summarize our current understanding on the composition and function of the metastatic BME and discuss the recent advances how miRNAs can modulate pathological interactions in the bone environment.

Keywords: breast cancer, bone metastases, microRNA, bone microenvironment, osteoclast, osteoblast

\section{INTRODUCTION}

Breast cancer is one of the most common malignancies in the world. Approximately $12 \%$ of women are diagnosed with breast cancer during their lifetime (1). After successful treatment of the primary tumor that often comprises surgery, adjuvant chemo- and radiation therapy, and the administration of anti-hormonal drugs, patients frequently suffer from distant metastases even decades after a disease-free interval (2). Bone is the most common site for breast cancer metastases, and approximately $70 \%$ of patients with advanced breast cancer suffer from osteolytic bone metastases (3). Osteolytic metastases are frequently associated with skeletal-related events (SREs), including fractures and spinal cord compression, that are often accompanied by severe pain and hypercalcemia (4).

In a physiological context, bone mass is maintained by the balanced activities of matrix-producing osteoblasts (OBs) that originate from mesenchymal cells and can become matrix-entrapped osteocytes (OCYs), and bone-resorbing osteoclasts (OCs) that arise from the hematopoietic lineage (5). $\mathrm{OC}$ function and bone resorption is stimulated by the receptor activator of NFKB ligand (RANKL) that is expressed in membrane-bound and soluble forms by OBs and OCYs (Figure 1). The activity is restricted by osteoprotegerin, which is a soluble decoy receptor against RANKL (6). Under 


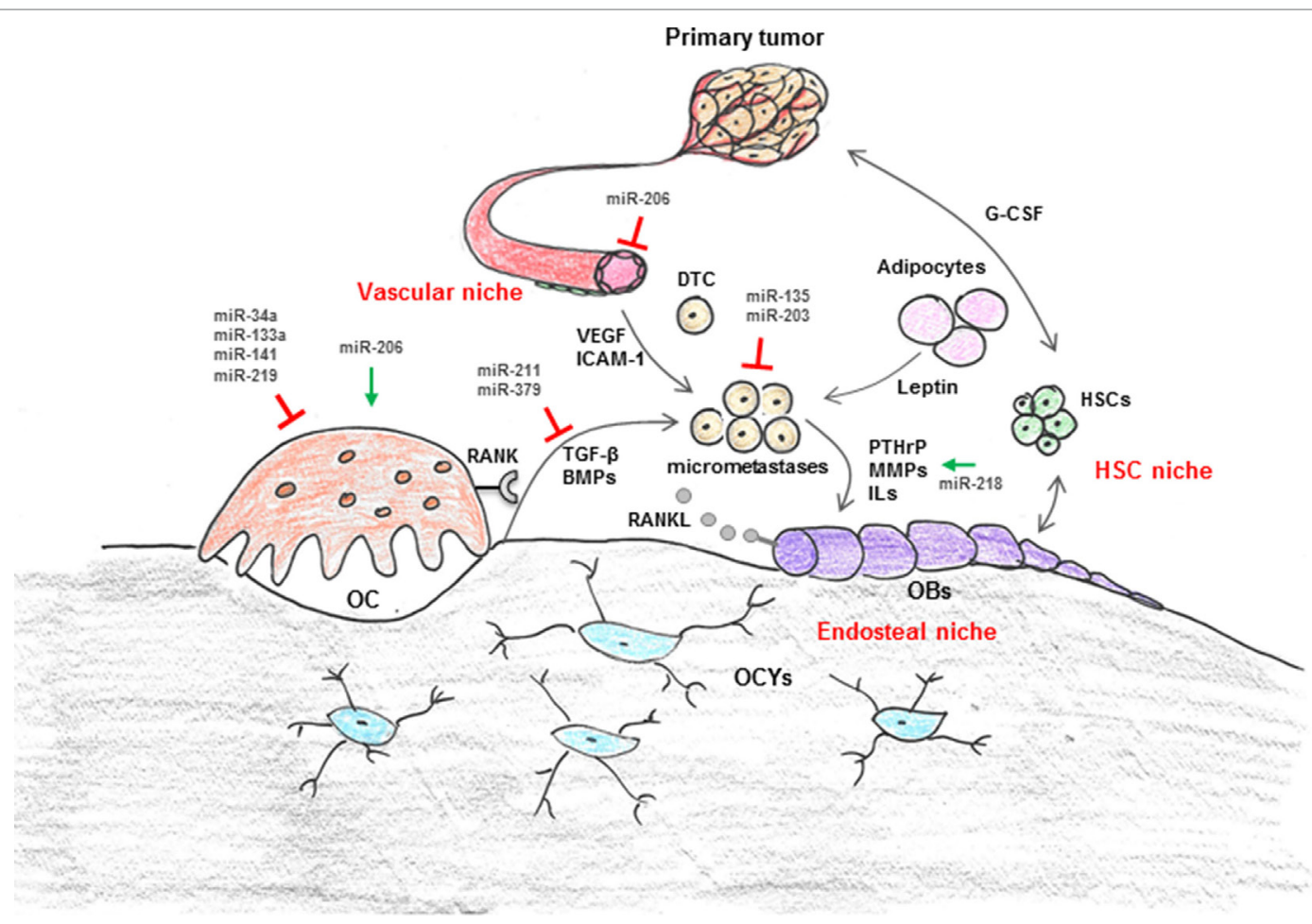

FIGURE 1 Regulation of cellular interaction in breast cancer bone metastasis by microRNA (miRNAs). The bone microenvironment (BME) is composed of cellular entities, including hematopoietic stem cells (HSC niche), osteoblasts (OBs), osteoclasts (OCs), and adipocytes (endosteal niche) as well as vascular endothelial cells and pericytes (vascular niche). These niches are suggested to control survival, dormancy, and growth of disseminated tumor cells (DTCs) through production of cytokines (i.e., leptin, G-CSF, VEGF, etc.) and intracellular signals in addition to cell-to-cell contact. In a physiological context, the highly coordinated cross talk between bone-forming OBs and bone-resorbing OCs maintains bone mass. OC function is regulated via OB and osteocyte (OCYs) derived RANKL. In the context of metastatic breast cancer disease, breast cancer cells severely disturb the balance between bone formation and resorption through secretion of various growth factors and cytokines [i.e., interleukins (ILs), parathyroid hormone-related protein (PTHrP), matrix metalloproteinases (MMPs), RANKL]. Recently, it has also been suggested that cells from the primary tumor themselves modify the distant microenvironment, for example through systemic factors (i.e., VEGF, TGF- $\beta$, G-CSF, miRNAs), in order to make it more attractive for DTCs. Several components of the BME are negatively (red blocks) or positively (green arrows) regulated by miRNAs.

pathological conditions, for instance in the context of metastatic breast cancer disease, breast cancer cells colonize the bone marrow microenvironment and severely disturb the balance between bone formation and bone resorption (7). This multi-directional process termed "vicious cycle" perpetuates metastatic bone destruction (8).

MicroRNAs (miRNAs) are small non-coding RNAs and key regulators of various biological processes including bone remodeling and cancer progression $(9,10)$. miRNAs bind to the $3^{\prime} \mathrm{UTR}$ of their target mRNAs, and depending on the degree of complementarity interfere with the mRNA stability and/or by block protein translation (9). Abnormal miRNA expression has been implicated in the pathology of osteoporosis, primary bone tumors, and bone metastases of various cancers (11-14). Furthermore, in vivo delivery of miRNA mimics or miRNA antagonists has been established as an attractive therapeutic approach to reverse bone degeneration, or to prevent cancer-induced bone diseases $(15,16)$. Thus, miRNAs can be used as therapeutic targets and may provide a novel tool to treat breast cancer-induced osteolytic disease.

Several miRNAs have been identified to regulate breast cancer cell-intrinsic oncogenic properties, such as proliferation, migration, and invasion (17-19). However, how miRNAs regulate non-cell autonomous interactions in the bone microenvironment (BME) remains largely unknown. This review highlights the recent understanding of the role of miRNAs in the metastatic $\mathrm{BME}$ and their potential use as therapeutic targets to modulate the pathological environment and limit disease progression.

\section{METASTATIC BONE DISEASE}

Bone is the most prevalent metastatic site for breast cancer cell colonization and growth. Bone metastasis is a complex multistep process starting from the dissemination of malignant cells into bloodstream, survival of these circulating tumor cells (CTCs) in the circulation, homing to distant organs and eventually metastases formation in the distant site (2). Disseminated tumor cells (DTCs) can be detected in the bone marrow of approximately $30 \%$ of breast cancer patients and predict for poor overall survival, breast cancer-specific survival, and disease-free survival compared to patients without DTCs (20).

Once bone metastases occur, the disease is incurable, and treatment remains palliative (21). The standard of care for patients with bone metastases comprises anti-resorptive drugs that reduce 
the progression of bone destruction and increase survival (22). For instance, bisphosphonates are well established in the treatment of osteolytic disease. Bisphosphonates are incorporated into the bone matrix and taken up by OCs during bone resorption, leading to $\mathrm{OC}$ apoptosis and a consecutive reduction of bone resorption (22). An alternative therapeutic approach is the use of the human monoclonal antibody Denosumab (Xgeva ${ }^{\circledR}$ ) that inhibits RANKL and has been shown to delay the time to first and subsequent SRE in breast cancer patients (23). Although breast cancer patients greatly benefit from the use of bisphosphonates and Denosumab, a better understanding of the control of the "vicious cycle" in the BME and the underlying cellular and molecular mechanisms is needed as it is likely to help identifying novel therapeutic concepts to restrict SREs.

\section{TUMOR MICROENVIRONMENT (TME) - THE BME IN BREAST CANCER BONE METASTASIS}

Over the last decade, a variety of preclinical studies have emphasized the contribution of the TME to disease progression (24-28). The TME comprises the cellular environment in which the tumor exists, the surrounding extracellular matrix, and signaling molecules. Several aspects of how the TME impacts cancer growth are well established such as the role of endothelial cells in tumor angiogenesis $(29,30)$. However, others including the role of the TME in mediating tumor cell invasion, dissemination, and metastasis remain poorly defined (31).

Circulating tumor cells have a high affinity for bone, in particular areas of active bone remodeling (32). The highly balanced cross talk between OBs and OCs, the presence of various other bone marrow-derived cell populations and soluble factors including osteopontin (OPN) and matrix metalloproteinases (MMPs) make bone an attractive site ("soil") for DTCs ("seeds"). Nearly almost a century ago Steven Pagets' "seed and soil theory" proposed that therapies to modify the TME might be of equal importance as therapies targeted against the tumor cells themselves (33). Hence, cells of the BME are becoming increasingly recognized as potential therapeutic targets for breast cancer bone metastasis $(24-27,34,35)$.

Upon their arrival in bone, DTCs encounter a heterogeneous BME, which is composed of various cells originating from either hematopoietic or mesenchymal stem cells (HSCs, MSCs, respectively) (Figure 1). These include lymphoid and myeloid lineage cells (e.g., immune cells, megakaryocytes, erythrocytes, and macrophages such as OCs) as well as adipocytes and bone and connective tissue-forming cells (e.g., chondrocytes and $\mathrm{OBs}$ ). In addition, the BME contains a dense, interconnected vascular system which maintains hematopoiesis and osteogenesis $(36,37)$. Within bone, these various cellular entities form supporting microenvironments, "niches," which are thought to regulate tumor cell homing, survival, and dormancy $(28,38-41)$ (Figure 1). The most well-studied niches are the HSC-, endosteal- (OBs, OCs), and vascular niche (vascular endothelial cells, pericytes). Both, the endosteal and the vascular niche control self-renewal, differentiation, and proliferation of HSCs through cell-to-cell contacts as well as by producing a variety of cytokines and intracellular signals (42-45). It is thought that tumor cells respond, similar like HSCs, to these signals. Among the most well studied pathways is the CXCL12/CXCR4 axis. CXCL12 or stromal cell-derived factor-1 (SDF-1) is produced and secreted by bone marrow stromal cells, primarily the $\mathrm{OB}$, endothelial, and epithelial cells (46) (Figure 1). Its cognate receptor CXCR4 is expressed in high levels on various cancer cell lines, including MDA-MB-231 (47). Overexpression of CXCR4 in MDA-MB-231 cells increases bone metastasis, and very recently, it has been demonstrated that both newly and established metastases were anchored in the bone marrow by CXCR4/CXCL12 interactions $(48,49)$. Further niche signals are suggested to include OPN, vascular adhesion molecule-1, intercellular adhesion molecule-1, chemokines such as Interleukins (ILs) and various growth factors, including bone morphogenetic proteins, Transforming growth factor- $\beta 1$ (TGF- $\beta$ ), and Vascular endothelial growth factor (VEGF) (50-52) (Figure 1). Emerging data also implicate the importance of the immune- and bone marrow adipocyte niche in bone metastasis $(28,53,54)$. Studies by Templeton et al. highlighted the role of adipocytes, one of the most abundant stromal components in the BME, in breast cancer cell osteotropism and early colonization by demonstrating that adipokines, including leptin, promote the migration of MDA-MB-231 breast cancer cells to human bone tissue fragments in vitro (28). Nevertheless, exact mechanisms that guide DTCs toward the metastatic site in bone remain to be established. Recently, it was proposed that cells from the primary tumor themselves modify the distant (bone) microenvironment, for example through systemic factors (i.e., VEGF, TGF- $\beta$, LOX, G-CSF, miRNAs), in order to make it more attractive for DTCs $(27,55,56)$.

Given the heterogeneity of the BME, the fate of DTCs might be determined by the nature of their arrival site within bone. A recent review by Croucher et al. suggests that long-term dormancy might be supported when tumor cells face quiescent/static microenvironments (e.g., endosteal surfaces covered by bone lining cells or stable vasculature), whereas active, dynamic BMEs including areas of osteoclastic bone resorption and sprouting vasculature foster proliferation and/or reactivation of dormant tumor cells $(26,57)$.

Once activated, breast cancer cells secrete growth factors, such as Parathyroid hormone-related protein $(P T H r P)$, ILs, and MMPs, which stimulate OBs to produce excessive amounts of RANKL and other cytokines (58-60). RANKL increases OCs activity and subsequent bone degradation. During bone resorption, matrix-derived growth factors, e.g., TGF- $\beta 1$ are released into the metastatic microenvironment and further stimulate cancer cell proliferation (7). This "vicious cycle" perpetuates metastatic bone destruction leading to osteolytic disease (8). Therefore, targeting the BME, for instance by miRNAs, to disable this cycle is not only scientifically interesting but also clinically relevant approach.

\section{TUMOR-DERIVED miRNAs INFLUENCING THE BME}

MicroRNAs have been recently recognized as key regulators of various biological processes, including cancer progression and 
metastasis. miRNAs are small (20-22 nucleotides in length), endogenous non-coding RNAs which posttranscriptionally regulate mRNA stability and protein translation (9). More than 1,800 miRNAs are expressed in humans and according to prediction tools, each miRNA regulates numerous target genes (61-63). An important feature of miRNAs is that miRNAs can be encapsulated in extracellular vehicles and released to bloodstream (64-66), which makes them attractive minimal or non-invasive source of biomarkers of various diseases, including bone disorders $(67,68)$.

MicroRNAs expressed by tumor cells can act as master regulators of bone metastases formation by targeting metastasis-driving factors and consequently altering cancer cell behavior (17-19). In addition, tumor-derived miRNAs can exert their oncogenic or tumor-suppressive action by altering the BME. A specific feature of bone metastatic breast cancer cells is that they exhibit pathologically elevated expression of bone-related genes [e.g., Runt-related transcription factor 2 (Runx2)] and signaling pathways, including the Wnt pathway (69-71). Runx2 is necessary for normal bone formation but often dysregulated in bone metastatic breast cancer cells due to a downregulation of Runx2-targeting miRNAs, including miR-135 and miR-203 (72). Runx2 promotes tumor growth in bone and knocking down Runx2 in cancer cells protects from breast cancer-induced osteolytic disease, positioning Runx2 as an attractive target to reduce bone metastatic burden (73). Indeed, pharmacological delivery of synthetic miR-135 and miR-203 mimics into metastatic breast cancer cells reduces Runx 2 protein abundance and consequently, diminishes tumor growth and spontaneous metastasis to bone (72). Furthermore, reconstitution of miR-135 and miR-203 greatly impairs tumor growth in the BME and alleviates osteolytic disease. The bone protecting effect occurred through downregulation of several metastasis-promoting Runx2 target genes, including IL-11, MMP-13, and PTHrP, and subsequent inhibition of OC activity (72).

Similarly, Wnt signaling promotes $O B$ differentiation and function under physiological conditions but a hyper activation of the signaling pathway is implicated in numerous cancers, including metastatic breast cancer $(70,74)$. In bone metastatic breast cancer cells, Wnt signaling induces the expression of PTHrP thus aggravating the vicious cycle (75). In OBs, Wnt signaling and miR-218 create a positive feed-forward loop through targeting of Wnt inhibitors, such as Dkk1 and sFRP1 by miR-218 (76). Similarly, miR-218 activates Wnt signaling in metastatic breast cancer cells (76). Consequently, miR-218 enhances MDAMB-231 cell proliferation and increases the expression of Wnt target genes in a Wnt-dependent manner $(76,77)$. Furthermore, miR-218 promotes PTHrP secretion in cancer cells and subsequent activation of RANKL in OBs, leading to an enhanced OB-mediated OC differentiation. Importantly, antagonizing miR218 reversed these effects in vitro and prevented the formation of cancer-induced osteolytic lesions in vivo (77). Tumor-derived osteolytic cytokines are also regulated by miR-211 and miR-379 (78). Both miRNAs prevented TGF- $\beta$-induced upregulation of IL-11 and downregulated several genes involved in TGF- $\beta$ pathway (78). Thus, miR-211 and miR-379 block the vicious cycle by preventing breast cancer cells from receiving signals from the metastatic BME.
Besides regulating the vicious cycle of bone metastasis, tumorderived miRNAs, including miR-126, have been established in pathological angiogenesis in the BME (79). miR-126, which is silenced in breast cancer cells with bone metastatic potential, suppresses endothelial recruitment and metastatic angiogenesis in a non-cell autonomous manner and, importantly, inhibits bone metastatic colonization of breast cancer cells. The underlying mechanism involves a coordinated targeting of two newly identified pro-metastatic genes; insulin-like growth factor binding protein 2 (IGFPB2) and c-Mer tyrosine kinase (MERTK). Metastatic breast cancer cells secrete IGFPB2 that acts on insulin-like growth factor (IGF1) type I receptor on endothelial cells and modulates IGF1 activation and subsequently endothelial recruitment. In addition, endothelial recruitment is promoted upon cleavage of cMERTK receptor from the breast cancer cells, which antagonizes the binding of GAS6 to endothelial MERTK receptors. A series of elegant loss-of-function and replacement experiments revealed individual components of the pro-angiogenic IGFPB2/IGF1/ IGF1R and GAS6-MERTK signaling pathways as direct targets of miR-126 and establish miR-126 as a crucial factor regulating endothelial interactions in the metastatic BME (79).

Recently, miRNAs released from cancer cells in microvesicles or exosomes have been shown to directly control cell-cell interactions in the BME. For instance, miR-192, which is highly abundant in metastatic lung cancer, can be secreted from the cancer cells in extracellular vesicles and transferred to endothelial cells (80). Cancer cell-derived miR-192 is efficiently taken up by endothelial cells in vitro and in vivo, and inhibits tumor-induced angiogenesis leading to reduced metastatic burden and decreased osteolytic disease in mice.

\section{TARGETING THE BME BY miRNAs}

Since OC activity is a hallmark of metastatic bone disease, the current treatment as well as the majority of basic research is focusing on restricting OC activity and attenuating pathological bone resorption. Along these lines, several studies have established miRNAs as crucial regulators of pathological OC differentiation. Especially miRNAs that suppress bone resorption provide an attractive approach to limit disease progression $(81,82)$. For instance, miR-34a was recently reported to inhibit physiological and pathological OC differentiation and to block osteoporosis and cancer-induced bone destruction (83). Using several genetic mouse models, Krzezinski et al. demonstrated that OC-targeted overexpression of miR-34a impairs bone resorption resulting in resistance of bone metastases. Conversely, deletion of miR-34a activated OCs leading to reduced bone mass and exacerbated bone metastasis burden. Mechanistically, miR-34a targets a homeodomain protein TG-interacting factor 2 , a novel positive regulator of osteoclast differentiation and function. In a therapeutically relevant setting, systemic delivery of miR-34a mimic oligonucleotides via chitosan nanoparticles diminished bone metastatic burden and osteolysis (83). Since miR-34a had no direct effect of cancer cell proliferation these effects are likely mediated by osteoclasts and possibly other cells in the BME emphasizing the importance of the TME in disease progression. 
In another comprehensive study, a group of miRNAs was shown to regulate tumor-induced osteoclast differentiation. Five miRNAs, miR-33a, miR-133a, miR-141, miR-190, and miR-219 were downregulated during osteoclast differentiation under physiological and pathophysiological conditions (84). Among them, miR-133a, miR-141, and miR-219 impaired osteoclast differentiation in vitro by targeting important osteoclast-promoting factors Mitf, Mmp14, Calcitonin receptor, and Traf5. In vivo administration of synthetic miR-141 and miR-219 oligonucleotides reduced physiological bone resorption, impaired tumor growth in bone and prevented pathological bone destruction. In this study, two miRNAs, miR-16 and miR-378 secreted in exosomes by osteoclasts were found to be increased in patients with bone metastases compared to healthy controls and the expression correlated with bone metastasis burden (84). Interestingly, miR-378 promotes tumor growth, angiogenesis, and tumor cell survival through the repression of tumor suppressors SuFu and Fus-1 (85). Although beyond this review, it is important to emphasize that miRNA signatures are being pursued as novel clinical diagnostic targets for predicting metastasis or therapeutic resistance $(1,4)$.

miR-214 is strongly increased in bone specimen of breast cancer patients with osteolytic bone metastases compared to healthy controls and patients without bone involvement (86). Consistently, osteoclasts isolated from mice with bone metastases express significantly higher levels of miR-214 compared to controls. In addition, miR-214 is elevated in bone tissue and serum of aged patients with fractures and miR-214 expression is accompanied with increased osteoclast activity and bone resorption, indicating that miR-214 regulates bone remodeling in health and disease $(87,88)$. Indeed, miR-214 is expressed and has a functional role in both OBs and osteoclasts. In OBs, miR-214 inhibits differentiation in vitro and bone formation in vivo by targeting the activating transcription factor 4 . As a consequence, delivery of OB-targeted antagomiR-214 in osteoporotic mice increased bone formation and restored bone mass (87). In contrast, in osteoclasts, miR-214 promotes osteoclast function and bone resorption through inhibition of the phosphatase and tensin homolog and Traf3, a negative regulator of NFkB signaling and osteoclast differentiation $(86,89)$. As a consequence, osteoclast-targeted deletion of miR-214 reduced bone resorption and prevented the development of osteolytic lesions in mice (86). The number and size of nonbone metastases was not changed in mice lacking miR-214 in the osteoclast lineage indicating that the tumor-suppressive effect of bone metastases is mediated by the BME. Importantly, pharmacological delivery of osteoclast targeted (D-Asp8)liposome conjucated antimiR-214 oligonucleotides reduced

\section{REFERENCES}

1. McGuire A, Brown JAL, Kerin MJ. Metastatic breast cancer: the potential of miRNA for diagnosis and treatment monitoring. Cancer Metastasis Rev (2015) 34:145-55. doi:10.1007/s10555-015-9551-7

2. Pantel K, Brakenhoff RH. Dissecting the metastatic cascade. Nat Rev Cancer (2004) 4:448-56. doi:10.1038/nrc1370

3. Roodman GD. Mechanisms of bone metastasis. Discov Med (2004) 4:144-8. physiological and pathological bone resorption and protected from osteolytic bone metastases, suggesting that inhibition of miR-214 could provide an attractive therapeutic strategy to prevent pathological bone destruction (86).

Intriguingly, miR-214 is secreted from osteoclasts in exosomes into circulation and acts on local and distant OBs (88). Treatment of wild-type mice with exosomes isolated from mice with osteoclast-targeted overexpression of miR-214 reduced bone formation demonstrating that the osteoclast-derived miR-214 is fully functional in OBs. This was further supported by an increased bone formation after systemic administration of antagomiR-214 encapsulated in osteoclast-targeted (D-Asp)8-liposomes (88). Given the dual bone anabolic and anti-catabolic effect of antagomiR-214, a systemic delivery of antago-miR-214 might provide a potent strategy to not only prevent osteolytic disease but also reverse existing lesions.

\section{PERSPECTIVES}

MicroRNAs play a pivotal role in tissue development and homeostasis. Therefore, dysregulation of individual miRNAs is implicated in several pathological conditions, including the onset and progression of metastatic bone disease. While the role of miRNAs regulating oncogenic properties of tumor cells is relatively well established, the direct or indirect regulation of TME by miRNAs has only recently started to be uncovered. In particular, miRNAs that mediate cell-cell interactions in the BME provide a novel therapeutic approach to disable the pathological cross talk in the bone marrow. For instance, identifying and targeting miRNAs that are pathologically elevated in osteoclasts and promote the vicious cycle could offer novel strategies for diagnosis and treatment of bone metastases. Although the evidence is thus far exclusively based on preclinical data, the applications of using miRNAs as adjuvant tools in bone metastases targets are very promising. Therefore, a better understanding of the complex miRNA-mediated cellular interactions is not only scientifically interesting but also critical in transmitting the knowledge from the bench to bedside.

\section{AUTHOR CONTRIBUTIONS}

$\mathrm{M}-\mathrm{TH}$ and HT reviewed literature and wrote the manuscript.

\section{FUNDING}

$\mathrm{M}-\mathrm{TH}$ is supported by a post-doctoral fellowship from the Humboldt Foundation. HT received funding from the Deutsche Forschungsgemeinschaft (TA1154/1-1).

4. D'Oronzo S, Brown J, Coleman R. The role of biomarkers in the management of bone-homing malignancies. JBone Oncol (2017) 9:1-9. doi:10.1016/j. jbo.2017.09.001

5. Baron R, Hesse E. Update on bone anabolics in osteoporosis treatment: rationale, current status, and perspectives. J Clin Endocrinol Metab (2012) 97:311-25. doi:10.1210/jc.2011-2332

6. O'Brien CA, Nakashima T, Takayanagi H. Osteocyte control of osteoclastogenesis. Bone (2013) 54:258-63. doi:10.1016/j.bone.2012.08.121 
7. Weilbaecher KN, Guise TA, McCauley LK. Cancer to bone: a fatal attraction. Nat Rev Cancer (2011) 11:411-25. doi:10.1038/nrc3055

8. Mundy GR. Metastasis to bone: causes, consequences and therapeutic opportunities. Nat Rev Cancer (2002) 2:584-93. doi:10.1038/nrc867

9. Lian JB, Stein GS, van Wijnen AJ, Stein JL, Hassan MQ, Gaur T, et al. MicroRNA control of bone formation and homeostasis. Nat Rev Endocrinol (2012) 8:212-27. doi:10.1038/nrendo.2011.234

10. Drusco A, Croce CM. MicroRNAs and cancer: a long story for short RNAs. Adv Cancer Res (2017) 135:1-24. doi:10.1016/bs.acr.2017.06.005

11. Taipaleenmäki H. Regulation of bone metabolism by microRNAs. Curr Osteoporos Rep (2018) 16(1):1-12. doi:10.1007/s11914-018-0417-0

12. Browne G, Taipaleenmäki H, Stein GS, Stein JL, Lian JB. MicroRNAs in the control of metastatic bone disease. Trends Endocrinol Metab (2014) 25:320-7. doi:10.1016/j.tem.2014.03.014

13. van der Deen M, Taipaleenmäki H, Zhang Y, Teplyuk NM, Gupta A, Cinghu S, et al. MicroRNA-34c inversely couples the biological functions of the runtrelated transcription factor RUNX2 and the tumor suppressor p53 in osteosarcoma. J Biol Chem (2013) 288:21307-19. doi:10.1074/jbc.M112.445890

14. Iorio MV, Croce CM. MicroRNA dysregulation in cancer: diagnostics, monitoring and therapeutics. A comprehensive review. EMBO Mol Med (2012) 4:143-59. doi:10.1002/emmm.201100209

15. Taipaleenmäki H, Bjerre Hokland L, Chen L, Kauppinen S, Kassem M. Mechanisms in endocrinology: micro-RNAs: targets for enhancing osteoblast differentiation and bone formation. Eur J Endocrinol (2012) 166:359-71. doi:10.1530/EJE-11-0646

16. Krzeszinski JY, Wan Y. New therapeutic targets for cancer bone metastasis. Trends Pharmacol Sci (2015) 36:360-73. doi:10.1016/j.tips.2015.04.006

17. Zoni E, van der Pluijm G. The role of microRNAs in bone metastasis. J Bone Oncol (2016) 5:104-8. doi:10.1016/j.jbo.2016.04.002

18. Zhao Q, Luo F, Ma J, Yu X. Bone metastasis-related microRNAs: new targets for treatment? Curr Cancer Drug Targets (2015) 15:716-25. doi:10.2174/ 1568009615666150629102408

19. Croset M, Kan C, Clézardin P. Tumour-derived miRNAs and bone metastasis. Bonekey Rep (2015) 4:688. doi:10.1038/bonekey.2015.56

20. Fontanella C, Fanotto V, Rihawi K, Aprile G, Puglisi F. Skeletal metastases from breast cancer: pathogenesis of bone tropism and treatment strategy. Clin Exp Metastasis (2015) 32:819-33. doi:10.1007/s10585-015-9743-0

21. Coleman R. Bone targeted treatments in cancer - the story so far. J Bone Oncol (2016) 5:90-2. doi:10.1016/j.jbo.2016.03.002

22. Coleman RE. Impact of bone-targeted treatments on skeletal morbidity and survival in breast cancer. Oncology (Williston Park) (2016) 30:695-702.

23. Stopeck AT, Lipton A, Body J-J, Steger GG, Tonkin K, de Boer RH, et al. Denosumab compared with zoledronic acid for the treatment of bone metastases in patients with advanced breast cancer: a randomized, double-blind study. J Clin Oncol (2010) 28:5132-9. doi:10.1200/JCO.2010.29.7101

24. Haider M-T, Holen I, Dear TN, Hunter K, Brown HK. Modifying the osteoblastic niche with zoledronic acid in vivo-potential implications for breast cancer bone metastasis. Bone (2014) 66:240-50. doi:10.1016/j.bone.2014.06.023

25. Ubellacker JM, Haider M-T, DeCristo MJ, Allocca G, Brown NJ, Silver DP, et al. Zoledronic acid alters hematopoiesis and generates breast tumorsuppressive bone marrow cells. Breast Cancer Res (2017) 19:23. doi:10.1186/ s13058-017-0815-8

26. Ghajar CM, Peinado H, Mori H, Matei IR, Evason KJ, Brazier H, et al. The perivascular niche regulates breast tumour dormancy. Nat Cell Biol (2013) 15:807-17. doi: $10.1038 /$ ncb2767

27. Cox TR, Rumney RMH, Schoof EM, Perryman L, Høye AM, Agrawal A, et al. The hypoxic cancer secretome induces pre-metastatic bone lesions through lysyl oxidase. Nature (2015) 522:106-10. doi:10.1038/nature14492

28. Templeton ZS, Lie W-R, Wang W, Rosenberg-Hasson Y, Alluri RV, Tamaresis JS, et al. Breast cancer cell colonization of the human bone marrow adipose tissue niche. Neoplasia (2015) 17:849-61. doi:10.1016/j.neo.2015.11.005

29. Bissell MJ, Radisky D. Putting tumours in context. Nat Rev Cancer (2001) 1:46-54. doi:10.1038/35094059

30. Folkman J. Role of angiogenesis in tumor growth and metastasis. Semin Oncol (2002) 29:asonc02906q0015. doi:10.1053/sonc.2002.37263

31. Hanahan D, Weinberg RA. Hallmarks of cancer: the next generation. Cell (2011) 144:646-74. doi:10.1016/j.cell.2011.02.013

32. Brown HK, Ottewell PD, Evans CA, Holen I. Location matters: osteoblast and osteoclast distribution is modified by the presence and proximity to breast cancer cells in vivo. Clin Exp Metastasis (2012) 29:927-38. doi:10.1007/s10585012-9481-5

33. Paget S. The distribution of secondary growths in cancer of the breast. 1889 . Cancer Metastasis Rev (1989) 8:98-101.

34. Zheng H, Bae Y, Kasimir-Bauer S, Tang R, Chen J, Ren G, et al. Therapeutic antibody targeting tumor- and osteoblastic niche-derived jagged1 sensitizes bone metastasis to chemotherapy. Cancer Cell (2017) 32:731-47.e6. doi:10.1016/ j.ccell.2017.11.002

35. Haider M-T, Hunter KD, Robinson SP, Graham TJ, Corey E, Dear TN, et al. Rapid modification of the bone microenvironment following short-term treatment with cabozantinib in vivo. Bone (2015) 81:581-92. doi:10.1016/j.bone. 2015.08.003

36. Kusumbe AP, Ramasamy SK, Adams RH. Coupling of angiogenesis and osteogenesis by a specific vessel subtype in bone. Nature (2014) 507:323-8. doi:10.1038/nature13145

37. Itkin T, Gur-Cohen S, Spencer JA, Schajnovitz A, Ramasamy SK, Kusumbe AP, et al. Distinct bone marrow blood vessels differentially regulate haematopoiesis. Nature (2016) 532:323-8. doi:10.1038/nature17624

38. Zalucha JL, Jung Y, Joseph J, Wang J, Berry JE, Shiozawa Y, et al. The role of osteoclasts in early dissemination of prostate cancer tumor cells. J Cancer Stem Cell Res (2015) 3:e1005. doi:10.14343/JCSCR.2015.3e1005

39. Wang H, Yu C, Gao X, Welte T, Muscarella AM, Tian L, et al. The osteogenic niche promotes early-stage bone colonization of disseminated breast cancer cells. Cancer Cell (2015) 27:193-210. doi:10.1016/j.ccell.2014.11.017

40. Shiozawa Y, Pedersen EA, Havens AM, Jung Y, Mishra A, Joseph J, et al. Human prostate cancer metastases target the hematopoietic stem cell niche to establish footholds in mouse bone marrow. J Clin Invest (2011) 121:1298-312. doi:10.1172/JCI43414

41. Shiozawa Y, Havens AM, Pienta KJ, Taichman RS. The bone marrow niche: habitat to hematopoietic and mesenchymal stem cells, and unwitting host to molecular parasites. Leukemia (2008) 22:941-50. doi:10.1038/leu.2008.48

42. Taichman RS. Blood and bone: two tissues whose fates are intertwined to create the hematopoietic stem-cell niche. Blood (2005) 105:2631-9. doi:10.1182/ blood-2004-06-2480

43. Psaila B, Lyden D, Roberts I. Megakaryocytes, malignancy and bone marrow vascular niches. J Thromb Haemost (2012) 10:177-88. doi:10.1111/j.1538-7836. 2011.04571.x

44. Calvi LM. Osteoblastic activation in the hematopoietic stem cell niche. Ann N Y Acad Sci (2006) 1068:477-88. doi:10.1196/annals.1346.021

45. Adams GB, Chabner KT, Alley IR, Olson DP, Szczepiorkowski ZM, Poznansky MC, et al. Stem cell engraftment at the endosteal niche is specified by the calciumsensing receptor. Nature (2006) 439:599-603. doi:10.1038/nature04247

46. Ponomaryov T, Peled A, Petit I, Taichman RS, Habler L, Sandbank J, et al. Induction of the chemokine stromal-derived factor-1 following DNA damage improves human stem cell function. J Clin Invest (2000) 106:1331-9. doi:10.1172/JCI10329

47. Müller A, Homey B, Soto H, Ge N, Catron D, Buchanan ME, et al. Involvement of chemokine receptors in breast cancer metastasis. Nature (2001) 410:50-6. doi: $10.1038 / 35065016$

48. Kang Y, Siegel PM, Shu W, Drobnjak M, Kakonen SM, Cordón-Cardo C, et al. A multigenic program mediating breast cancer metastasis to bone. Cancer Cell (2003) 3:537-49. doi:10.1016/S1535-6108(03)00132-6

49. Price TT, Burness ML, Sivan A, Warner MJ, Cheng R, Lee CH, et al. Dormant breast cancer micrometastases reside in specific bone marrow niches that regulate their transit to and from bone. Sci Transl Med (2016) 8:340ra73. doi:10.1126/scitranslmed.aad4059

50. McAllister SS, Gifford AM, Greiner AL, Kelleher SP, Saelzler MP, Ince TA, et al. Systemic endocrine instigation of indolent tumor growth requires osteopontin. Cell (2008) 133:994-1005. doi:10.1016/j.cell.2008.04.045

51. Lu X, Mu E, Wei Y, Riethdorf S, Yang Q, Yuan M, et al. VCAM-1 promotes osteolytic expansion of indolent bone micrometastasis of breast cancer by engaging $\alpha 4 \beta 1$-positive osteoclast progenitors. Cancer Cell (2011) 20:701-14. doi:10.1016/j.ccr.2011.11.002

52. Butler JM, Kobayashi H, Rafii S. Instructive role of the vascular niche in promoting tumour growth and tissue repair by angiocrine factors. Nat Rev Cancer (2010) 10:138-46. doi:10.1038/nrc2791

53. Malladi S, Macalinao DG, Jin X, He L, Basnet H, Zou Y, et al. Metastatic latency and immune evasion through autocrine inhibition of WNT. Cell (2016) 165:45-60. doi:10.1016/j.cell.2016.02.025 
54. Monteiro AC, Leal AC, Gonçalves-Silva T, Mercadante ACT, Kestelman F, Chaves SB, et al. T cells induce pre-metastatic osteolytic disease and help bone metastases establishment in a mouse model of metastatic breast cancer. PLoS One (2013) 8:e68171. doi:10.1371/journal.pone.0068171

55. Kaplan RN, Psaila B, Lyden D. Bone marrow cells in the "pre-metastatic niche": within bone and beyond. Cancer Metastasis Rev (2007) 25:521-9. doi:10.1007/ s10555-006-9036-9

56. Costa-Silva B, Aiello NM, Ocean AJ, Singh S, Zhang H, Thakur BK, et al. Pancreatic cancer exosomes initiate pre-metastatic niche formation in the liver. Nat Cell Biol (2015) 17:816-26. doi:10.1038/ncb3169

57. Croucher PI, McDonald MM, Martin TJ. Bone metastasis: the importance of the neighbourhood. Nat Rev Cancer (2016) 16:373-86. doi:10.1038/ nrc.2016.44

58. Powell GJ, Southby J, Danks JA, Stillwell RG, Hayman JA, Henderson MA, et al. Localization of parathyroid hormone-related protein in breast cancer metastases: increased incidence in bone compared with other sites. Cancer Res (1991) 51:3059-61.

59. Martin TJ. Manipulating the environment of cancer cells in bone: a novel therapeutic approach. J Clin Invest (2002) 110:1399-401. doi:10.1172/JCI0217124

60. Li J, Karaplis AC, Huang DC, Siegel PM, Camirand A, Yang XF, et al. PTHrP drives breast tumor initiation, progression, and metastasis in mice and is a potential therapy target. J Clin Invest (2011) 121:4655-69. doi:10.1172/ JCI46134

61. Lewis BP, Burge CB, Bartel DP. Conserved seed pairing, often flanked by adenosines, indicates that thousands of human genes are microRNA targets. Cell (2005) 120:15-20. doi:10.1016/j.cell.2004.12.035

62. Lim LP, Lau NC, Garrett-Engele P, Grimson A, Schelter JM, Castle J, et al. Microarray analysis shows that some microRNAs downregulate large numbers of target mRNAs. Nature (2005) 433:769-73. doi:10.1038/nature03315

63. Kozomara A, Griffiths-Jones S. miRBase: annotating high confidence microRNAs using deep sequencing data. Nucleic Acids Res (2014) 42:D68-73. doi:10.1093/nar/gkt1181

64. Valadi H, Ekström K, Bossios A, Sjöstrand M, Lee JJ, Lötvall JO. Exosomemediated transfer of mRNAs and microRNAs is a novel mechanism of genetic exchange between cells. Nat Cell Biol (2007) 9:654-9. doi:10.1038/ncb1596

65. Vickers KC, Palmisano BT, Shoucri BM, Shamburek RD, Remaley AT. MicroRNAs are transported in plasma and delivered to recipient cells by high-density lipoproteins. Nat Cell Biol (2011) 13:423-33. doi:10.1038/ ncb2210

66. Wang K, Zhang S, Weber J, Baxter D, Galas DJ. Export of microRNAs and microRNA-protective protein by mammalian cells. Nucleic Acids Res (2010) 38:7248-59. doi:10.1093/nar/gkq601

67. Weber JA, Baxter DH, Zhang S, Huang DY, Huang KH, Lee MJ, et al. The microRNA spectrum in 12 body fluids. Clin Chem (2010) 56:1733-41. doi:10.1373/clinchem.2010.147405

68. Hackl M, Heilmeier U, Weilner S, Grillari J. Circulating microRNAs as novel biomarkers for bone diseases - complex signatures for multifactorial diseases? Mol Cell Endocrinol (2016) 432:83-95. doi:10.1016/j.mce.2015.10.015

69. Sethi N, Kang Y. Dysregulation of developmental pathways in bone metastasis. Bone (2011) 48:16-22. doi:10.1016/j.bone.2010.07.005

70. Matsuda Y, Schlange T, Oakeley EJ, Boulay A, Hynes NE. WNT signaling enhances breast cancer cell motility and blockade of the WNT pathway by sFRP1 suppresses MDA-MB-231 xenograft growth. Breast Cancer Res (2009) 11:R32. doi:10.1186/bcr2317

71. Pratap J, Lian JB, Stein GS. Metastatic bone disease: role of transcription factors and future targets. Bone (2011) 48:30-6. doi:10.1016/j.bone.2010.05.035

72. Taipaleenmäki H, Browne G, Akech J, Zustin J, van Wijnen AJ, Stein JL, et al. Targeting of Runx2 by miR-135 and miR-203 impairs progression of breast cancer and metastatic bone disease. Cancer Res (2015) 75:1433-44. doi:10.1158/0008-5472.CAN-14-1026

73. Pratap J, Lian JB, Javed A, Barnes GL, van Wijnen AJ, Stein JL, et al. Regulatory roles of Runx2 in metastatic tumor and cancer cell interactions with bone. Cancer Metastasis Rev (2006) 25:589-600. doi:10.1007/s10555-006-9032-0
74. Blagodatski A, Poteryaev D, Katanaev VL. Targeting the Wnt pathways for therapies. Mol Cell Ther (2014) 2:28. doi:10.1186/2052-8426-2-28

75. Johnson RW, Merkel AR, Page JM, Ruppender NS, Guelcher SA, Sterling JA. Wnt signaling induces gene expression of factors associated with bone destruction in lung and breast cancer. Clin Exp Metastasis (2014) 31:945-59. doi:10.1007/s10585-014-9682-1

76. Hassan MQ, Maeda Y, Taipaleenmaki H, Zhang W, Jafferji M, Gordon JAR, et al. miR-218 directs a Wnt signaling circuit to promote differentiation of osteoblasts and osteomimicry of metastatic cancer cells. J Biol Chem (2012) 287:42084-92. doi:10.1074/jbc.M112.377515

77. Taipaleenmäki H, Farina NH, van Wijnen AJ, Stein JL, Hesse E, Stein GS, et al. Antagonizing miR-218-5p attenuates Wnt signaling and reduces metastatic bone disease of triple negative breast cancer cells. Oncotarget (2016) 7:79032-46. doi:10.18632/oncotarget.12593

78. Pollari S, Leivonen S-K, Perälä M, Fey V, Käkönen S-M, Kallioniemi O. Identification of microRNAs inhibiting TGF- $\beta$-induced IL-11 production in bone metastatic breast cancer cells. PLoS One (2012) 7:e37361. doi:10.1371/ journal.pone.0037361

79. Png KJ, Halberg N, Yoshida M, Tavazoie SF. A microRNA regulon that mediates endothelial recruitment and metastasis by cancer cells. Nature (2012) 481:190-4. doi:10.1038/nature10661

80. Valencia K, Luis-Ravelo D, Bovy N, Antón I, Martínez-Canarias S, Zandueta C, et al. miRNA cargo within exosome-like vesicle transfer influences metastatic bone colonization. Mol Oncol (2014) 8:689-703. doi:10.1016/j.molonc. 2014.01.012

81. Kagiya T. MicroRNAs and osteolytic bone metastasis: the roles of microRNAs in tumor-induced osteoclast differentiation. J Clin Med (2015) 4:1741-52. doi:10.3390/jcm4091741

82. Ell B, Kang Y. MicroRNAs as regulators of tumor-associated stromal cells. Oncotarget (2013) 4:2166-7. doi:10.18632/oncotarget.1625

83. Krzeszinski JY, Wei W, Huynh H, Jin Z, Wang X, Chang T-C, et al. miR-34a blocks osteoporosis and bone metastasis by inhibiting osteoclastogenesis and Tgif2. Nature (2014) 512:431-5. doi:10.1038/nature13375

84. Ell B, Mercatali L, Ibrahim T, Campbell N, Schwarzenbach H, Pantel K, et al. Tumor-induced osteoclast miRNA changes as regulators and biomarkers of osteolytic bone metastasis. Cancer Cell (2013) 24:542-56. doi:10.1016/j. ccr.2013.09.008

85. Lee DY, Deng Z, Wang C-H, Yang BB. MicroRNA-378 promotes cell survival, tumor growth, and angiogenesis by targeting SuFu and Fus-1 expression. Proc Natl Acad Sci U S A (2007) 104:20350-5. doi:10.1073/pnas.0706901104

86. Liu J, Li D, Dang L, Liang C, Guo B, Lu C, et al. Osteoclastic miR-214 targets TRAF3 to contribute to osteolytic bone metastasis of breast cancer. Sci Rep (2017) 7:40487. doi:10.1038/srep40487

87. Wang X, Guo B, Li Q, Peng J, Yang Z, Wang A, et al. miR-214 targets ATF4 to inhibit bone formation. Nat Med (2012) 19:93-100. doi:10.1038/ $\mathrm{nm} .3026$

88. Li D, Liu J, Guo B, Liang C, Dang L, Lu C, et al. Osteoclast-derived exosomal miR-214-3p inhibits osteoblastic bone formation. Nat Commun (2016) 7:10872. doi:10.1038/ncomms 10872

89. Zhao C, Sun W, Zhang P, Ling S, Li Y, Zhao D, et al. miR-214 promotes osteoclastogenesis by targeting Pten/PI3k/Akt pathway. RNA Biol (2015) 12:343-53. doi:10.1080/15476286.2015.1017205

Conflict of Interest Statement: The authors declare that the research was conducted in the absence of any commercial or financial relationships that could be construed as a potential conflict of interest.

Copyright (c) 2018 Haider and Taipaleenmäki. This is an open-access article distributed under the terms of the Creative Commons Attribution License (CC BY). The use, distribution or reproduction in other forums is permitted, provided the original author(s) and the copyright owner are credited and that the original publication in this journal is cited, in accordance with accepted academic practice. No use, distribution or reproduction is permitted which does not comply with these terms. 